\title{
Conversational Dominance and the Asymmetric Distribution of Roles in Cross-Sex Conversations
}

\author{
Gang Zhou ${ }^{1}$, Xiaochun Niu ${ }^{2}$ \\ School of Foreign Languages, Dalian University of Technology, Dalian City, China
}

*Corresponding Author: Gang Zhou, School of Foreign Languages, Dalian University of Technology, Dalian City, China

\begin{abstract}
This paper aims to study the different roles both men and women play when they communicate in friendly cross-sex conversations. It also attempts to explain if men and women's daily interactions can testify those persistent stereotypes of women and men as language users. The five stretches of conversational segments analyzed in the paper were multi-party cross-sex casual conversations. These extracts were videorecorded in the sitting-room of our flat. The three interactants as international students in Wales, come from China. They are two boys and one girl. The findings show that women display a greater tendency to ask questions; women are more likely to adopt a strategy of "silent protest" after they have been interrupted or have received a delayed minimal response. And men are more likely to interrupt the speech of their conversational partners.
\end{abstract}

Keywords: Conversational Dominance, Cross-Sex, Gender Stereotype, Sequential

\section{INTRODUCTION}

Studies have shown that when men and women attempt to communicate equally in friendly cross-sex conversations they do not play the same role in interaction (Maltz \& Borker, 1998). One of the pervasive stereotypes of women as language users is that they are unflagging talkers. Many lexical items testify to this belief, which negatively evaluate women as talkers: they are gossips, chatterers, prattlers, gas-bags, chatterboxes who talk too much (Poynton, 1989). However, those lexical items intended to describe males are dominant, interruptive, loud, concise and blunt (Bradac, 1990). A number of recent studies show that this common stereotype of females as talkers is a gross caricature and that in conversational interaction between males and females, men usually have the upper hand. Topics are determined by, or in deference to, men - by men interrupting, or talking over women in order to get the floor if women do not automatically give up the right (Poynton, 1989). Such behaviour can clearly be oseen as dominance display on the part of men, and is by no means always submitted to without protest by women. Behind such displays would seem to lie evaluations of both female and male topic choices and of the point or purpose of different kinds of interaction, that is their nature as genres, that are widely shared by males and females.

Tannen (1990) argues that one of the most widely cited findings to emerge from research on gender and language is that men interrupt women. She believes an interruption is a hostile act, a kind of conversational bullying. Interruption is an intrusion, a trampling on someone else's right to the floor, an attempt to dominate. Aries (1996) also states that interruptions provide a behavioral measure of dominance in everyday social experience because they involve a violation of the current speaker's right to speak, are used to usurp that person's turn, and are used to control the topic of conversation. Interruptions thus provide a measure that we can use to determine whether the greater power and dominance of men in society is reflected in ordinary face-to-face interaction between men and women. But Zimmerman and West (1975) believe that men's dominance in conversation parallels their dominance in society. They see interruptions and topic control as male display of power. One of the most widely contested areas of gender and language is whether men interrupt their conversation partners more often than do women (Aries, 1996; Tannen, 1994). Zimmerman and West (1975) were among the first researchers to investigate the topic by observing casual conversation between same and mixed-gender pairs. They found that in conversations among people of the same sex, the 
interruptions were equally divided between the two speakers. In conversations between men and women, on the other hand, men did almost all of the interruptions of women's speech (Aries, 1996; Kristin, 1998).

It has long been assumed that women and men differ in their use of language and styles in conversations. These differences are supposed to represent the social divisions between women and men. Few researchers will disagree that women and men's speech styles are different. As Tannen (1990) points out, if women speak and hear a language of connection and intimacy, while men speak and hear a language of status and independence, then communication between men and women can be like cross-cultural communication, prey to a clash of conversational styles. Talbot (1998, p: 98) states, "Advice and sympathy; or to put it another way, problem-solving and problem-sharing. This is one of the contrasts between men and women's expectations in conversation..." Maltz and Borker (1998) have summarized in full length women's and men's different features in cross-sex conversations as follows:

\subsection{Women's Features}

1. Women display a greater tendency to ask questions.

2. Women are more likely than men to make utterances that demand or encourage responses from their fellow speakers.

3. Women show a greater tendency to make use of positive minimal responses.

4. Women are more likely to adopt a strategy of "silent protest" after they have been interrupted or have received a delayed minimal response.

5. Women show a greater tendency to use the pronouns "you" and "we".

\subsection{Men's Features}

1. Men are more likely to interrupt the speech of their conversational partners, that is, to interrupt the speech of women.

2. Men are more likely to challenge or dispute their partners' utterances.

3. Men are more likely to ignore the comments of the other speaker, that is, to offer no response or acknowledgment at all.

4. Men use more mechanisms for controlling the topic of conversation, including both topic development and the introduction of new topics, than do women.

5. Men make more direct declarations of fact or opinion than do women.

Maltz and Borker (1998) argue that there are two understandings of topic flow and topic shift which may be major potential for miscommunication in cross-sex conversations, men operate with a system in which topic is fairly narrowly defined and adhered to until finished and in which shifts between topics are abrupt, while women have a system in which topic is developed progressively and shifts gradually. Mutual understanding is symmetrical, and this symmetry contributes to a sense of community. But giving advice is asymmetrical. It frames the advice giver as more knowledgeable, more reasonable, more in control --- in a word, one-up. And this contributes to the distancing effect (Tannen, 1990).

According to Itakura (2001), conversational dominance refers to an overall pattern of asymmetry measured in terms of the distribution of controlling actions between speakers over the course of an interaction along (1) sequential, (2) participatory and (3) quantitative dimensions. Dominance in conversation can be identified along three dimensions: sequential, participatory and quantitative. On the dimensions of sequential and participatory dominance, local instances of controlling action are identified in terms of controlling actions, which are followed by complying actions, i.e. successful actions, or non-complying actions, i.e. attempted controlling action. In sequential dominance, controlling actions are identified at the level of turns. Quantitative dominance is analysed by comparing the total number of words uttered by each speaker. In cases where the results from these three dimensions differ, Itakura considers sequential dominance the strongest indicator of conversational dominance as it is most closely related to topic development. 


\section{Methodology}

The five stretches of conversational segments analyzed in the paper were multi-party cross-sex casual conversations. These extracts were video-recorded in the sitting-room of our flat. The three interactants as international students in Wales, come from China. They are two boys and one girl. One of the boys is 23 years old, named $\mathrm{Wu}$, and the other boy is 21 , named Wang. The girl is 20 years old, named Liu. With their agreement, and their kind cooperation, their conversations were videorecorded in separate days. Because they occasionally dined together in the evening sharing what they cooked at weekends, when it is usually the only time they can meet each other, most of the extracts of their cross-sex talk or casual conversations took place at dinner, or right after dinner at weekends. All these conversations occurred naturally (i.e. uncontrived) without any external interference or any of our guidance.

The three conversationalists were subsequently informed of the researchers' recording and their consent obtained. A video-camera was put in the corner of the sitting-room, so that it would appear less obtrusive. In the process of transcription, identifying references were disguised and the tape erased after the transcript was completed and checked, thus protecting the anonymity of the persons involved. Thus, consent was uniformly obtained after recording, and no refusals to permit the use of the tape or complaints about the covert procedure were encountered.

Transcription was done according to a set of conventions modeled after those suggested by Coupland and Jarworski (2003) (see Appendix II). Some instances of silences (or pauses) between utterances were timed by a wrist watch. Those portions of the tapes actually transcribed were selected by the criteria that a segment exhibits a pattern of (a) noticeable silence between speaker turns and/or (b) instances of simultaneous speech.

This research will follow the three dimensions put forward by Itakura (2001) to explore and prove male dominance and the asymmetric distribution of roles in cross-sex conversations through the study of the stretches of casual talk collected. Moreover, it will try to answer the following questions through the study of the data: In a male-female conversation, do men or women usually dominate? Do women use overlaps more frequently in conversation than men? Do men use interruptions more often than women?

\section{Analyses of the Recorded CONVERSATIONS BASEd ON ITAKURA'S THREe-Dimension MODEL}

\subsection{Sequential Dominance}

According to Itakura (2001), sequential dominance is defined as a speaker's tendency to control the other speaker(s) with respect to the direction of the interaction, or how speakers share initiating and responding roles. In other words, it refers to an overall pattern where one speaker tends to control the direction of conversation, measured by the way in which the speakers share initiating and responding moves when creating sequences of utterances. In sequential dominance, controlling actions are identified at the level of turns. Sequential dominance is assumed to be the strongest indicator of conversational dominance as it captures the speakers' behaviour in each exchange which is the basic unit of conversational organization. It is also closely related to development of the topic.

In terms of turn allocation, in Extract 1(see Appendix I), Wang (a boy) took 5 turns, Wu (the other boy) took 5 turns as well, and the girl named Liu took 3 turns. In total, the boys have taken 10 turns to 3 turns taken by the girl in their cross-sex conversation. In Extract 2, Wang took 6 turns, Wu took 4 turns and Liu took 4 turns. In total, the boys have taken 10 turns to 4 turns taken by the girl in their cross-sex conversation. In Extract 3, Wang took 6 turns, Wu took 7 turns and Liu took 4 turns. In total, the two boys have taken 13 turns to 4 turns taken by the girl in their cross-sex conversation. In Extract 4, Wang took 8 turns, Wu took 7 turns and Liu took 5 turns. In total, the boys have taken 15 turns to 5 turns taken by the girl. Finally, in Extract 5, Wang took 8 turns, Wu took 6 turns and Liu took 5 turns. In total, the two boys have taken 14 turns to 5 turns taken by the girl in their cross-sex conversation. In sum, in the five extracts the two boys have taken $75 \%$ of the turn takings, and the girl has taken $25 \%$ of the turn takings.

In Extract 1, most of the time Wang initiated, and Wu responded. Although Liu's turns consisted of initiating moves, she received negative or non-complying responses. In Extract 2 and 5, Liu's 
turns consisted of responding moves, she did not initiate at all. In Extract 5 she initiated once, and she attempted to control the development of the topic, but she failed to elicit her expected responses from the two boys to her initiating move. Instead the two boys succeeded in eliciting their expected responses to their initiating moves either from each other or from the girls. In other words, the boys have initiated all of the apparently unilateral topic changes.

The simple statistical figures mentioned above, the distribution of initiating moves and responding moves, and the boys' successful controlling actions and the girl's attempted controlling actions in the five extracts (see Appendix I) have basically revealed that in the cross-sex conversations the boys have dominated the conversations, and decided the development of the topics. They have controlled the large amount of time in their conversational interaction. As Maltz and Borker (1998) point out, men are more likely to ignore the comments of the other speaker, that is, to offer no response or acknowledgment at all; men use more mechanisms for controlling the topic of conversation, including both topic development and the introduction of new topics, than do women. These two features have been displayed obviously in the data collected.

\subsection{Participatory Dominance}

Participatory dominance refers to a speaker's tendency to control the other speaker(s) in terms of speaking rights, in particular through overlaps and interruptions, which affect the speaker(s)'s participation in interaction (Itakura, 2001). In other words, it often refers to patterns of asymmetry where one speaker's holding on to the turn until completion following an interruption or overlap leads to the other speaker(s)'s leaving the turn incomplete and therefore losing the chance to participate in the conversation.

Although overlaps and interruptions are different from each other, they are similar in the sense that they are not a normal feature of the turn-taking system (Itakura, 2001). Tannen (1993) also contends that if one speaker repeatedly overlaps and another repeatedly gives way, the resulting communication is asymmetrical, and the effect is domination.

The normal turn-taking system includes clean transitions between speaker turns, the floor is passed back and forth at regular short intervals. And the listener is ready to begin a turn at a transition place where the speaker is at the completion of his/her utterance.

An overlap occurs when two speakers speak at the same time at a turn transition relevance point (TRP) where both speakers have a right to complete their respective utterances. In the five excerpts of conversations (see Appendix I) among the three interlocutors, Wang and $\mathrm{Wu}$, the two boys behaved as frequent overlappers, and Liu, the girl,had been overlapped most of the time. For example, in Extract 1: Wang overlapped the other two interlocutors, especially the girl, in his turn 10; in Extract 2: Wang's turn 8 and turn 12; in Extract 3: Wang's turn 10 and turn 15; in Extract 4: Wang's turn 10 and turn 16. Wu frequently overlapped the other two as well, for instance, in Extract 1: Wu's turn 4; in Extract 2: Wu's turn 3 and turn 14; in Extract 3: Wu's turn 4 and turn 11; in Extract 4: Wu's turn 5 and turn 15; and finally in Extract 5: Wu's turn 21. In these instances of overlaps, those between the two boys were cooperative and positive overlaps, because they overlapped each other and won out equally, there was symmetry and no domination. But when the girl was overlapped, she abandoned or withdrew her utterances, which had restricted her chance of participation in their cross-sex conversations. Thus, these overlaps become interruptions in the negative or power-laden sense (Tannen, 1993).

According to Itakura (2001), interruptions also relate to the speaker's chance to complete the turn. But they are caused by the interrupter's violation of turn-taking rules rather than mishap. In Extract 2:

15 Liu: ...I miss the seafood like...

16 Wang: the first thing I'm going to do when I go back

home is to eat, eat and eat again every day... 
In turn 15, Liu was interrupted by Wang who started his utterance in the middle of Liu's utterance. Wang completed the turn while Liu withdrew, which suggests that she was prevented from participating in interaction because of Wang's violation of the turn-taking rules. In Extract 4:

14 Wang: ... =no in my hometown we like to drink Long Kou Beer in China, every city

has its own favorite brand and...

$15 \mathrm{Wu}:$

Three Star Beer tastes good, very

famous in my province...

In turn14, Wang was interrupted by Wu before Wang completed his turn or utterance. This is an interruption because the second speaker began while the first speaker was in the middle of a word (and). In Extract 5:

3 Liu: ... I have never thought about it at all that means...

$4 \mathrm{Wu}$ :

don't hurry to go back home

and get married (teasingly)...

In turn 3 Liu was interrupted by Wu who started his utterance in the middle of Liu's utterance of a word (means), which prevented Liu from participating in the interaction.

Due to the two boys' frequent overlaps and interruptions, the girl's floor has often been deprived of. Therefore, she has remained silence most of the time, just as Maltz and Borker (1998) point out, women are more likely to adopt a strategy of "silent protest" after they have been interrupted or have received a delayed minimal response.

\subsection{Quantitative Dominance}

Quantitative dominance refers to a pattern where one of the speakers makes a greater contribution towards the text of a conversation than the other. It tends to be analysed in two major ways: distribution of the number of words between two speakers and turn length fro each speaker (Itakura, 2001). If the two speakers produce a similar number of words, it can be assumed that both speakers have participated more or less equally. Otherwise, one speaker may have caused the other speaker's participation in the creation of the mutual text to be reduced. In such cases, the former can be assumed to be dominant and the latter dominated along the dimension of quantitative dominance. In the data, it is not hard to find who have uttered most of the words in the light of the number of turns between the two boys and the girl. In addition, most of the girl's utterances are short, and some are uncompleted. Although there is an unbalance of sex, in general the two boys have controlled the development of the topics and the direction of conversational interaction.

\section{CONClusions}

The analyses based on the recorded data have partly proved that: women display a greater tendency to ask questions; women are more likely to adopt a strategy of "silent protest" after they have been interrupted or have received a delayed minimal response. And men are more likely to interrupt the speech of their conversational partners, that is, to interrupt the speech of women; men are more likely to ignore the comments of the other speaker, that is, to offer no response or acknowledgment at all; men use more mechanisms for controlling the topic of conversation, including both topic development and the introduction of new topics, than do women.

It is to be stressed, however, that transcriptions cannot represent the recordings in their full detail. They are always and necessarily selective. Besides, due to the multi-party conversations between two boys and one girl, the results tend to be subjective, although they seem to have demonstrated that men talk more than women and tend to dominate interactions. As Tannen (1993) contends that in trying to understand how speakers use language, we must consider the context. For example, in the five extracts, the girl has behaved as a silent listener most of the time. It may be because she has been 
frequently overlapped and interrupted, she remains silence as a protest. Apart from this, perhaps because the topic areas raised by the boys do not interest her, she does not feel motivated to participate in the interaction (in instance, in Extract 5). Just as West, Lazar and Kramarae (1997) point out, silence can mean different things in different situations, to different women and men in different cultures. Therefore, in future researches, the cultural differences and impacts on communication behaviors and communication styles should be further explored.

In sum, after conducting this small study, the researchers believe that issues other than gender are very important in interaction. It has been found that many studies are quick to put people into categories. Our relationship to the other person may matter much more than their gender. Similarly, a person may break out of their gender stereotype and display an entirely unexpected characteristic. It is believed that if we are to work on communication issues, we must be willing to explore our individual tendencies and our present situation. It is only with awareness that we can change.

\section{REFERENCES}

[1] Aries, E. (1996). Men and Women in Interaction: Reconsidering the Differences. New York, Oxford: OXFORD UNIVERSITY PRESS

[2] Coupland, J. \& Jarwoski, A. (2003). Transgression and Intimacy in Recreational Talk Narratives. Research on Language and Social Interaction. Vol. 36, No. 1, pp. 85-106. Lawrence Erbaum Associates, Inc.

[3] takura, H. (2001). Conversational Dominance and Gender. Amsterdam, Philadelphia: John Benjamins Publishing Company.

[4] Kristin, J. A \& Campbell, L. (1998). Meta-Analyses of Gender Effects on Conversational Interruption: who, what, when, where, and how. http://www.findarticles.com/cf_0/m2294/n 3-4_v39/21227867/ p1/ article.jhtml

[5] Maltz, D. N., \& Borker, R. A. (1998). A Cultural Approach to Male-Female Miscommunication. In Coates, Jennifer (ed.) Language and Gender: A Reader. BLACKWELL Publishers.

[6] Poynton, C. (1989). Language and gender: making the difference. Oxford, New York, Toronto, New Delhi, Bombay, Singapore, Hong Kong, Tokyo and Melbourne: Oxford University Press

[7] Talbot, M. M. (1998). Language and Gender: An Introduction. Polity Press.

[8] Tannen, D. (1990). You Just Don't UNDERSTAND: Women and Men in Conversation. London: VIRAGO PRESS.

[9] Tannen, D. (1993). The Relativity of Linguistic Strategies: Rethinking Power and Solidarity in Gender and Dominance. In Tannen, D. (ed.) Gender and Conversational Interaction. New York, Oxford: Oxford UNIVERSITY PRESS.

[10] West, C., Lazar, M. M. \& Kramarae, C. (1997). Gender in Discourse. In van Dijk, T. A. (ed.) Discourse as Social Interaction. Vol. 2, pp. 119-39. London, Thousand Oaks, New Delhi: SAGE Publications.

[11] Zimmerman, D. \& West, C. (1975). Sex Roles, Interruptions and Silences in Conversation. In Barrie Thorne and Nancy Henley (eds) Language and Sex: Difference and Dominance. New Bury House, Rowley, MA, pp. 105-29.

\section{APPENDIX I}

\section{Transcription}

\section{Extract 1}

Two male students and one female student, friendly flat-mates in Cardiff University, in the sittingroom, while they were eating their dinner together in the evening. One boy is named Chen(Wang) (21 years), the other is named Jia (Wu)(23 years), and the girl is named Li (Liu)(20 years). (All the Chinese names are pseudonyms.)

1. Wang: ...this afternoon our landlord phoned me, he said he would come to check the

2. house to see if any maintenance would be needed

3. Wu: he will do it by himself ((doubtfully)) ?

4. Wang: you know the cost of labour here is expensive he

5. should repaint the flat and replace the appliances to increase its value

6. $\mathrm{Wu}$ :

costly to do that 
7. Liu: the mushroom is salty (.) didn't you find it ?

8. Wu: I found it ok (.)

9. Wang: I think my tutors are strict I received low marks in one of my assignments last semester

10. Wu: =yeah I spent lots of time on my last coursework but I didn't get a distinction

11. Liu: next time when I cook the chicken chunks I won't put in green peppers

12. Wang:

I've given up the idea of a

13. distinction

14. Liu: the dishes have turned cold you men have talked too much

15. Wang: yes madame (laughter)

16. $\mathrm{Wu}: \quad$ (laughter)...

\section{Extract 2}

On a Saturday evening, $\mathrm{Wu}$, Wang and Liu were eating dinner together in the sitting-room again.

1. Wang: ... there is too much oil in the soup we should have put more vegetable into it

2. Liu: you can scoop it out

[

3. Wu: I miss the roasted duck I used to buy half of a duck with a

4. bottle of beer back home (.) oh what a great time

5. Liu: you are daydreaming (slight giggle)

6. Wang: (laughter) which kind of duck do you like better Peking Duck or Cantonese

7. $\operatorname{Duck}($.

8. Wu: I can't find any difference (.)

9. Liu: I think Peking Duck is too greasy

10. Wang: $\quad$ De Zhou Braised Chicken is No. 1 in China (.)

11. Wu: I've been fed up with the food here I like to take our deep-fried dough sticks milk for breakfast

12. Wang: you can make it by yourself if you like

13. Liu: hey gentlemen to make it requires skills

14. Wang: $\quad$ sometime we can try to make it

15.Liu: < everywhere you can find different and typical local food in China >

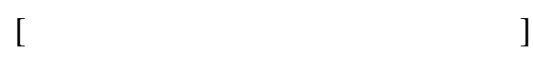

16. Wu: I miss the gourmet food in my hometown

17. Liu: I miss the seafood like...

[

18. Wang: the first thing I'm going to do when I go back home is to eat, eat and eat again every day...

\section{Extract 3}

The two boys and the girl were chatting right after dinner in the sitting-room on a Sunday evening.

1. Wang: ...hi Wu what are the girls like in Shanghai it is said they are slender but short

2. Wu: they are not as short as you said but Shanghaiese girls are very pretty=

3. Wang: = really (teasingly) (.) you know Cantonese girls are not tall even in terms

4. of the whole of China

[

5. Wu: that's because the climate is hot all years round in Guangdong

6. Miss Liu what kind of man do like most (teasingly) 
7. Liu: I don't want to discuss this with you ((slight laugh)) (.)

8. Wang: I have learned that the price for international calls has dropped dramatically

9. China Tea phone card is the cheapest

10. Wu: what about Saver card

11. Wang: China Tea card is worth 750 minutes but Saver card is just worth 550

12. minutes $=$

13. Wu: =the price competition among these companies is severe but sooner or

14. later the price for phone cards will rise again

$$
\text { [ }
$$

15. Wang: I have downloaded a film starred by

16. Jack Chan called The Tuxedo=

17. Wu: =oh it is a famous film I love Jack Chan's films

18. Liu: his films are all about bloody fights I don't think much of them

19. Wu: that's stimulating and exciting

20. Liu: < I like to see those films about animals >

[ ]

21. Wang: films of war are my favourites (.) let's go upstairs and enjoy the film=

22. Wu: =let's go ((laughter)) join us Miss Liu

23. Liu: no thanks I have to do some reading for my seminar tomorrow...

\section{Extract 4}

1. This stretch of talk took place on a Friday evening between the two boys and the girl in the sitting-room, where they were chatting together after dinner.

2. Wang: ...I heard that a Malay student in Manchester had earned 10, 000 pounds

3. after one year of study (.)

4. Liu: that's impossible otherwise everyday he had to work instead of study has

5. he got his degree?

6. Wang: I don't know then why not stay here for one more year to earn back our

7. tuition

8. Liu: I think it's better to get another degree if you have enough time and money

[

9. $\mathrm{Wu}:$

I have spent

10. all my money how can I afford to pay my tuition although I have plenty of

11. time (ironically)

12. Wang: what about going to Australia to get another Masters=

13. Wu: =yeah there tuition is much cheaper than here we work here for half of year

14. to save enough tuition (4.0)

15. Liu: hey one of my tutors was very funny today in class he taught us how

16. to earn money for instance how to invest in stocks (giggles)

17. Wang:

I think that's a good

18. topic to learn (.) in one of my courses there are only two in the class

19. (slight laugh) one tutor two students it's just like an interview

[

20. Wu:

a good chance to

21.practice speaking English eh (slight laugh) (6.0)

22. Wang: hi Wu in your hometown what's the most popular beer

23. Wu: Three Star Beer have you heard of it=

24. Wang: =no in my hometown we like to drink Long Kou Beer in China every city 25. has its own favorite brand and... 
[

26. Wu: Three Star Beer tastes good very famous in my

27. province

[

28. Wang: but Qing Dao Beer is famous across our country=

29. Wu: =yeah and Yan Jing Beer is as famous as it is (.)

30.Liu: (yawning)

31. Wang: in fact I like to drink our Chinese strong spirits (mmm) I love its fragrant

32. scent $=$

33. Wu: =it's also very strong (3.0)

34. Liu: I'm going upstairs good night...

Extract 5

This conversation tool place among Wang, Wu and Liu in the sitting-room on a Sunday afternoon.

1. Liu: ...I have received 87 marks in one of my courses um my average mark is $73 \%$

2. Wang: that's distinction you are qualified to apply for $\mathrm{PhD}$ if you like

3. Liu: I have never thought about it at all that means...

1. [

4. Wu: don't hurry to go back home and get married (teasingly)

5. Liu: what are you talking about please stop talking nonsense ((angry)) (5.0)

6. Wang: I called my mother last month I wonder she is waiting for my call (.)

7. Liu: every day I write to my mother on the internet

8. Wang: that's too frequent

9. Liu: I like to 'talk' to her it makes me less homesick (.)

10. Wang: have you ever heard of 'net love'

11. Wu: that's too popular one of my classmates got involved in this and in the end he got married to the girl

12. Liu: is it true?

13. Wang: that's nothing now 'one-night love' is a new fad

14. Liu: what is it

15. Wu: one man and a woman date on the internet and...

$$
\text { [ }
$$

16. Wang: either the man or the woman

invites the other to meet in a hotel (.)

17. Liu: what are they going to do there ((naively))

18. Wu: (laughter)

[ ]

19. Wang: you can guess what they are going to do in a hotel at night (laughter)

20. Liu: how can it be true how can you find such women < I have never heard of it > [ ]

21. Wu: there are many lonely men

and lonely women why not (slight laugh)...

\section{APPENDIX II}

\section{Transcription Conventions}

(.) untimed pause

(2.0) pause timed in seconds 
((shocked)) informal commentary on style or context of following utterance(s)

? indicates questioning function (not grammatical interrogative)

[ overlapping speech

[ ] entirely overlapped speech

$=$ 'latched' utterances (following each other without perceptible pause)

underlining unusually heavy emphasis

$<$ quiet speech

CAPS loud speech

( ) indecipherable data: best guess

\section{Authors' BIOGRAPHY}

Gang Zhou, is a professor, PhD, and a Fulbright Scholar teaching at School of Foreign Languages, Dalian University of Technology, who is specialized in Linguistics and Intercultural Communication studies.

Xiaochun Niu, is a professor teaching at School of Foreign Languages, Dalian University of Technology, who is specialized in Linguistics and Intercultural Communication studies.

Citation: Gang, Zhou, and Niu Xiaochun. "Conversational Dominance and the Asymmetric Distribution of Roles in Cross-Sex Conversations." International Journal on Studies in English Language and Literature (IJSELL), vol 5, no. 9, 2017, pp. 1-10. doi:http://dx.doi.org/10.20431/2347-3134.0509001.

Copyright: (C) 2017 Authors. This is an open-access article distributed under the terms of the Creative Commons Attribution License, which permits unrestricted use, distribution, and reproduction in any medium, provided the original author and source are credited. 